\title{
PENGOLAHAN LIMBAH RADIOAKTIF CAIR YANG MENGANDUNG DETERGEN DENGAN CARA OZONASI DIIKUTTI PENJERAPAN
}

\author{
Noor Anis Kundari, Emma Anajariyanti, Suryo Rancono \\ Sekolah Tinggi Teknologi Nuklir (Times New Roman 9pt) \\ noor_anis_kundari@yahoo.co.id (Times New Roman 9pt)
}

\begin{abstract}
ABSTRAK
PENGOLAHAN LIMBAH RADIOAKTIF CAIR YANG MENGANDUNG DETERJEN DENGAN OZON DIIKUTI PENJERAPAN. Ozon merupakan oksidator kuat untuk mendegradasi seryawa organik dan zeolit mempunyai karakter sebagai penjerap, kombinasi dari ke dua proses mempunyai potensi untuk mengolah limbah radioaktif cair yang mengandung deterjen. Penelitian ini bertujuan untuk menentukan efektivitas pengolahan limbah radioatif cair dengan metode ozonasi diikuti penjerapan dengan menghitung nilai faktor dekontaminasi (FD) dan efisiensi pengolahan (EP). Selain itu juga memperoleh persamaan kecepatan penurunan $C O D$ pada proses penjerapan setelah proses ozonasi. Penelitian dilakukan secara batch dengan variabel waktu. Laju produksi ozon mesin ozonizer yang digunakan pada penelitian ini adalah $1,0175 \times 10^{5} \mathrm{~g} \mathrm{O}_{3} /$ detik. Hasil penelitian menunjukkan nilai $C O D$ dan $T S$ turun seiring dengan semakin lamanya proses ozonasi, reaksi berlangsung pada orde satu dengan persamaan kecepatan penurunan $C O D:-r$ COD = $-\frac{\mathrm{d}[\mathrm{COD}]}{\mathrm{dt}}=0,034[\mathrm{COD}]^{\prime}$, nilai $F D$ dan EP dari proses penjerapan sebesar 145,773 dan $99,314 \%$.
\end{abstract}

Kata kunci: ozon, zeolit, limbah radioaktif, deterjen, kecepatan reaksi.

\section{ABSTRACT}

THE TREATMENT OF LIQUID RADIOACTIVE WASTE CONTAINING DETERGENT USING OZONE FOLLOWED BY SORPTION Ozone is a strong axidizer to degrade organic compounds and zeolite has a good characters character as a sorbent. The combination of the two processes has a potential to treat liquid radioactive wastes containing detergents. The purpose of this study was to determine whether the method of ozonation followed by sorption was effective for radioactive wastes containing detergents treatment by determine the FD and EP, and to formulate 
the rate equations of $C O D$ decreasing on ozonation process. The study was conducted in batch mode by varition of time. Ozone production rate of Ozonizer machine used in this study is $1,0175 \times 10^{-5} \mathrm{~g} \mathrm{O} /$ second. The results showed that the longer the ozonation process the lower concentration of both COD and TS, reaction took place at first order to $C O D$ with reduction rate equation: $-r_{C O D}=-\frac{\mathrm{d}[\mathrm{COD}]}{\mathrm{dt}}=0.034[\mathrm{COD}]^{\prime}$, while $F D$ and $E P$ values were 145.773 and $99.314 \%$ respectively.

Keywords: ozone, zeolite, radioactive waste, detergent, reaction rate

\section{INTRODUCTION}

Limbah radioaktif yang mengandung deterjen biasanya berasal dari cucian pakaian dan perlengkapan kerja radiasi di instalasi nuklir. Pakaian dan perlengkapan kerja yang dimaksud bisa berupa masker gas, pakaian, sarung tangan, topi, "shoecover", dan lain-lain yang apabila kotor dan terkontaminasi harus didekontaminasi dengan menggunakan sabun atau deterjen atau bahan pendekontaminasi yang lain (Gunandjar dkk, 2009).

Sebagai salah satu contoh adalah operasi pencucian pakaian kerja radiasi menggunakan detergen Persil yang dilakukan di Instalasi Pengolahan Limbah Radioaktif-Pusat Teknologi Limbah Radioaktif (IPLR-PTLR) ditimbulkan 133,7 $\mathrm{m}^{3}$ limbah cair per tahun yang mengandung detergen dengan konsentrasi maksimum $1,496 \mathrm{~g} / \mathrm{L}$ yang memiliki nilai COD (Chemical Oxygen Demand) $338 \mathrm{ppm}$, BOD(Biological Oxygen Demand) $189 \mathrm{ppm}$ dan aktivitas minimal $10^{-6} \mathrm{Cj} / \mathrm{m}^{3}$. Unsur radioaktif utama dalam limbah adalah Cs-137 yang berwaktu paruh 30 tahun. Detergen Persil digunakan karena sedikit menghasilkan buih sehingga dampak buruk pada proses evaporasi dapat dikurangi.

Evaporasi limbah detergen menimbulkan buih, sehingga untuk mencegah distilat terkontaminasi unsur radioaktif dibutuhkan bahan anti buih. Terjadinya buih pada proses evaporasi akan menyebabkan kenaikan jumlah cairan yang terlepas bersama uap dan lebih buruk lagi apabila terjadi "carry over" zat radioaktif ke distilat sehingga menurunkan nilai Faktor Dekontaminasi (FD). Biaya operasi evaporasi lebih mahal karena diperlukan uap air pemanas yang dibangkitkan dari pembakaran minyak dalam boiler, memerlukan bahan anti buih, dan asam nitrat penghilang kerak (Salimin, 2002 dan Mardini, 2006).

Teknologi ozonasi dan penjerapan menggunakan zeolit merupakan alternatif dalam teknologi pengolahan limbah. Ozon sebagai oksidator yang paling kuat setelah radikal hidroksida $\left(\mathrm{OH}^{*}\right)$, dapat dimanfaatkan dengan baik untuk mengoksidasi logam-logam berat (terlarut dalam air), mendegradasi senyawa-senyawa organik (termasuk juga senyawa organo-klorida dan aromatik), menghilangkan warna dan bau, ataupun rasa (Bismo dkk, 2008). Struktur zeolit yang berongga atau berpori sedemikjan rupa sehingga berpotensi sebagai penukar kation, penjerap, dan penyaring molekul serta sebagai katalis (Suhartanto,1999). Limbah radioaktif yang mengandung 
senyawa organik seperti deterjen persil yaitu deterjen yang mengandung rumus senyawa $\mathrm{CH}_{3}-\left(\mathrm{CH}_{2}\right) 10-\mathrm{CH}_{2}-\mathrm{OSO}_{3} \mathrm{Na}$ atau $\mathrm{Na}^{\prime} \mathrm{R}^{+} \mathrm{SO}_{3}$ dapat didegradasi menggunakan ozon, dan unsur radioaktif didalam limbah radioaktif tersebut dapat dipisahkan dengan penjerapan menggunakan zeolit. Disamping itu, beberapa kelebihan dari teknologi ini dapat disebutkan di antaranya: instalasi pengolahannya tidak membutuhkan tempat yang luas, proses pengolahan yang relatif cepat, tidak memerlukan pemakaian bahan kimia lain, efektifitas dan efisiensi yang tinggi dalam penguraian berbagai senyawa organik (Bismo, 2008).

Berdasarkan uraian di atas diperlukan proses alternatif lain selain proses evaporasi (yang telah ađa) untuk pengolahan limbah radioaktif cair yang mengandung deterjen. Proses ozonasi terhadap limbah radioaktif cair yang mengandung deterjen persil yang di dalamnya terdepat Cs-137 diharapkan dapat menurunkan COD dan TS, dan mendapatkan persamaan kinetika penurunan COD. Dilanjutkan penjerapan dengan zeolit yang telah diaktivasi diharapkan mampu menurunkan aktivitas dari Cs137 (FD dan EP yang diharapkan bernilai besar). Dengan demikian zeolit yang telah jenuh dapat langsung diimmobilisasi dan air limbah hasil olahan yang telah memenuhi baku mutu dapat dibuang ke lingkungan.

Zat organik dalam limbah radioaktif cair yang mengandung deterjen dapat didegradasi menggunakan ozon menurut persamaan sebagai berikut:

$\mathrm{COD}>>\div \mathrm{O}_{3} \rightarrow \mathrm{COD}<<\left[\mathrm{CO}_{2}+\mathrm{H}_{2} \mathrm{O}\right]^{*}$

Analisis data dengan metode integral dilakukan dengan cara menebak persamaan kecepatan dengan orde tertentu, lalu persamaan tersebut diintegralkan. Tebakan benar jika data diplotkan dan diperolah garis lurus sesuai dengan persamaan yang telah diintegralkan. Nilai $\mathrm{k}$ adalah slope dari plot garis lurus tersebut. Tebakan dilakukan pada orde 0 , orde 1 , dan orde 2 , hasil integrasi dapat dilihat pada persamaan (2) sampai (11).

$$
-r_{A}=-\frac{d C A}{d t}=k C A^{n}
$$

Jika reaksi orde 0 maka:

$$
\begin{aligned}
& -r_{A}=-\frac{d C A}{d t}-k C A^{0} \\
& \mathrm{dCA}=-\mathrm{kdt} . . . \cdots
\end{aligned}
$$

$$
\mathrm{CA}_{0}-\mathrm{CA}=\mathrm{kt}
$$




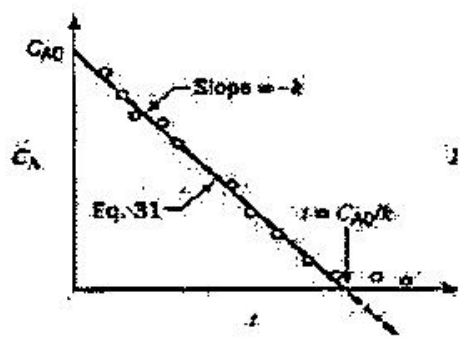

Gambar 1. pengujian untuk persamaan kecepatan orde 0

Jika reaksi mengikuti orde 1 maka:

$$
\begin{aligned}
& -r_{A}=-\frac{d \mathrm{CA}}{d t} \mathrm{kCA}^{1} \text {. } \\
& -\int_{C A D}^{C A} \frac{d C_{C A}}{C A}=\mathrm{k} \int_{0}^{t} d t \\
& \ln \frac{C A_{0}}{C A}=\text { kt. }
\end{aligned}
$$

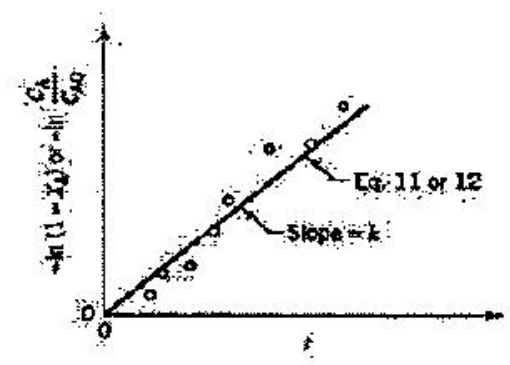

Gambar 2. pengujian untuk reaksi orde 1

Jika reaksi orde 2 maka

$$
\begin{gathered}
-\mathrm{r}_{\mathrm{A}}=-\frac{\mathrm{dCA}}{\mathrm{dt}}-\mathrm{kCA}^{2} \ldots \\
-\int_{C A \mathrm{~A}}^{\mathrm{CA}} \frac{\mathrm{dCA}}{C \mathrm{~A}^{\mathrm{2}}}=\mathrm{k} \int_{0}^{t} \mathrm{dt} \\
\frac{1}{C A}=\frac{1}{C A_{\mathrm{o}}}+\mathrm{kt}
\end{gathered}
$$




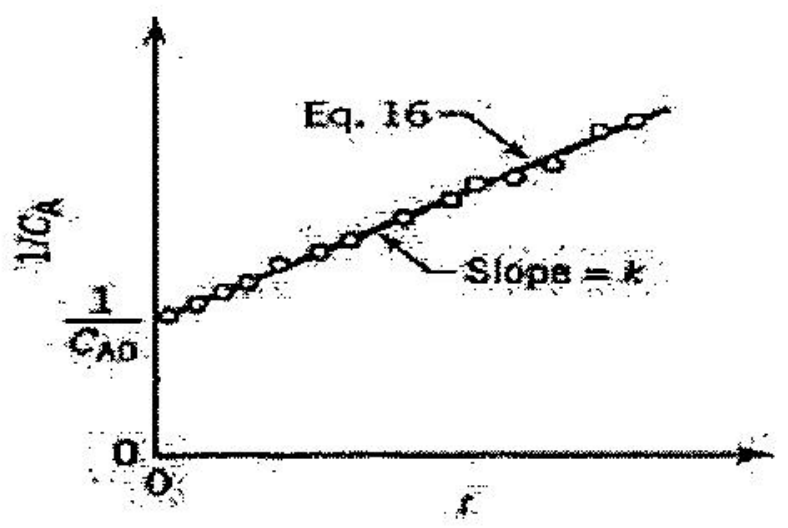

Gambar 3. Grafik pengujian untuk reaksi orde 2

dengan:

$-\mathrm{r}_{\mathrm{A}}=$ kecepatan penuruman $\mathrm{COD}$

$\mathrm{CA}=$ konsentrasis $\mathrm{COD}$

t = waktu

$k=$ konstanta kecepatan reaksi

$\mathrm{n}=$ orde reaksi

Unsur radioaklif yang terlarut dalam limbah cair organik (Cs-137) dapat dijerap menggunakan zeolit yang telah diaktivasi menurut persamaan (12) dan (13).

Cs-137+ Zeolit

$\longleftrightarrow$ ZeolitCs-137

$\mathrm{Cs}^{+}+$Zeolit-Na

Cs-Zeolit $+\mathrm{Na}^{+}$

Keefektifan pengolahan limbah limbah radioaktif cair yang mengandung deterjen dengan ozon diikuti dengan penjerapan dapat dievaluasi dengan menghitung faktor dekontaminasi (FD) dan efisiensi pemisahan (EP) dengan menggunakan persamaan (14) dan (15).

$$
\begin{array}{r}
\mathrm{FD}=\frac{C_{\mathrm{g}}}{G_{\mathrm{t}}} \ldots \ldots \ldots \ldots \\
\mathrm{EP}=\frac{G o-C_{t}}{C_{\mathrm{a}}} x 100 \% 0
\end{array}
$$

dengan :

$\mathrm{FD}=$ Faktor Dekontaminasi

$\mathrm{EP}=$ Efisiensi Pemisahan

Co $=$ konsentrasi awal sebelum penjerapan 
$\mathrm{Ct}=$ konsentrasi akhir setelah penjerapan

\section{METODE}

\section{Bahan}

Bahan-bahan yang digunakan adalah deterjen Persil, Rinso, $\mathrm{CsNO}_{3}$, Zeolit, HCL 1N. Bahan untuk standarisasi ozon meliputi Iodium $\left(\mathrm{I}_{2}\right)$, Kalium Iodida $(\mathrm{KI}), \mathrm{K}_{2} \mathrm{HPO}_{4}$, dan $\mathrm{Na}_{2} \mathrm{HPO}_{4}$. Bahan untuk analisis $\mathrm{COD}$ adalah larutan $\mathrm{K}_{2} \mathrm{Cr}_{2} \mathrm{O}_{7}, \mathrm{Ag}_{2}(\mathrm{SO})_{4}$ dalam $\mathrm{H}_{2} \mathrm{SO}_{4}$. Limbah simulasi dibuat dengan konsentrasi detcrjen Pcrsil 1,496 $\mathrm{g} / \mathrm{L}$ dengan kandungan Cesium 51,0204 ppm.

\section{Alat}

Mesin Ozonizer 100 Watt. Peralatan laboratorium meliputi peralatan gelas antaralain: gelas beker, corong, cawan porselin, labu ukur, erlenmeyer, pipet ukur, gelas ukur, ballpet, sendok sungu, spatula, stopwatch, sumbat tutup. Serta alat lain yang digunakan adalah furnace, screening, oven, neraca analitik. Alat uji yang digunakan meliputi seperangkat alat Spektrofotometer UV-Vis untuk keperluan standarisasi laju ozon, XRD untuk mengetahui jenis zeolit alam dan AAS untuk analisis kuantitatif unsur Cesium.

\section{.Cara Kerja}

Limbah cair yang mengandung detergen Persil dengan kadar 1,496 $\mathrm{g} / 1$ dan Cs 51,0204 diozonasi dengan waktu 2, 4, 6, 14,5, dan 16,1 jam. Proses ozonasi diulangi dengan konsentrasi yang sama menggunakan Rinso selama 1 jam. Setelah proses ozonasi limbah dijerap menggunakan zeolit selama 24 jam. Sebelum dan sesudah ozonasi dilakukan analisis COD, TS, dan $\mathrm{pH}$. Setelah proses penjerapan dilakukan analisis Cs dengan AAS.

\section{HASIL DAN PEMBAHASAN}

Hasil analisis XRD terhadap zeolit yang digunakan diperoleh data yang disajikan pada Tabel 1.

Tabcl 1. Data analisis XRD terhadap zeolit

\begin{tabular}{cccc}
\hline $\mathbf{2 \theta}$ & $\mathrm{d}(\boldsymbol{\AA})$ & Intensitas & Jenis mineral \\
\hline 10,0820 & 8,76650 & 43 & $\mathrm{Y}$ \\
12,3800 & 7,14393 & 17 & $\mathrm{Y}$ \\
22,4211 & 3,96214 & 100 & Mordenit \\
23,8000 & 3,73560 & 32 & $\mathrm{Y}$ \\
26,1400 & 3,40628 & 47 & Mordenit \\
27,0200 & 3,29730 & 36 & Mordenit \\
27,9966 & 3,18446 & 64 & clinoptilolite \\
30,2920 & 2,94818 & 31 & ANA Ga \\
31,2600 & 2,85906 & 11 & Mordenit \\
35,0000 & 2,56164 & 7 & Mordenit \\
\hline
\end{tabular}

Berdasarkan Tabel 1 dapat disimpulkan bahwa zeolit yang digunakan berjenis modernit. 
Ozonasi dengan variasi waktu antara 2-16 jam menghsilkan hubungan yang disajikan pada Tabel 2 .

Tabel 2. Data variasi ozonasi dengan waktu

\begin{tabular}{cccc}
\hline $\begin{array}{c}\text { Waktu ozona- } \\
\text { si (jam) }\end{array}$ & COD (ppm) & TS (ppm) & pH \\
\hline 0 & 499,019 & 1212 & 9 \\
2 & 458,481 & 1180 & 8 \\
4 & 445,019 & 1168 & 8 \\
6 & 423,478 & 1132 & 7 \\
14,5 & 323,855 & 1072 & 6 \\
16,1 & 270,005 & 1046 & 6 \\
\hline
\end{tabular}

Berdasarkan Tabel 2 dapat dinyatakan bahwa jika ozon diasukkan ke dalam air maka ozon bereaksi dengan air ataupun dengan komponen yang ada dalam air limbah secara langsung ataupun tidak langsung dengan membentuk radikal OH·. Zat-zat organik dalam limbah cair yang berasal dari senyawa detergen akan teroksidasi dan tcrhidrolisis menjadi senyawa lebih sederhana yang mengakibatkan penurunan nilai COD dan TS. Ssenyawa sederhana akan teroksidasi lagi, yang jika proses oksidasi sempurna akan dihasilkan karbon dioksida dan air. Oleh karena itu nilai pH juga turun.

Untuk merumuskan kecepatan penuruan $\mathrm{COD}$, berdasarkan data pada Tabel 2 dibuat hubungan menggunakan Persamaan (8) jika reaksi orde 1 yang menghasilkan Gambar 4 dan menggunakan Persamaan (11) jika dianggap reaksi orde 2. Pemilihan persamaan didasarkan pada nilai $R^{2}$ yang mendckati nilai 1 adalah yang sesuai.

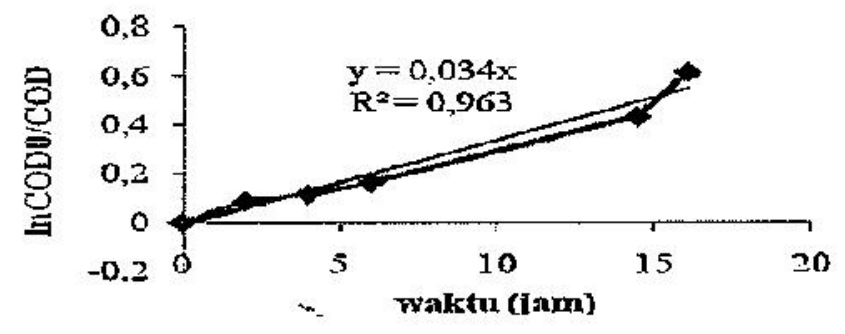

Gambar 4. Pengujian Reaksi Orde 1

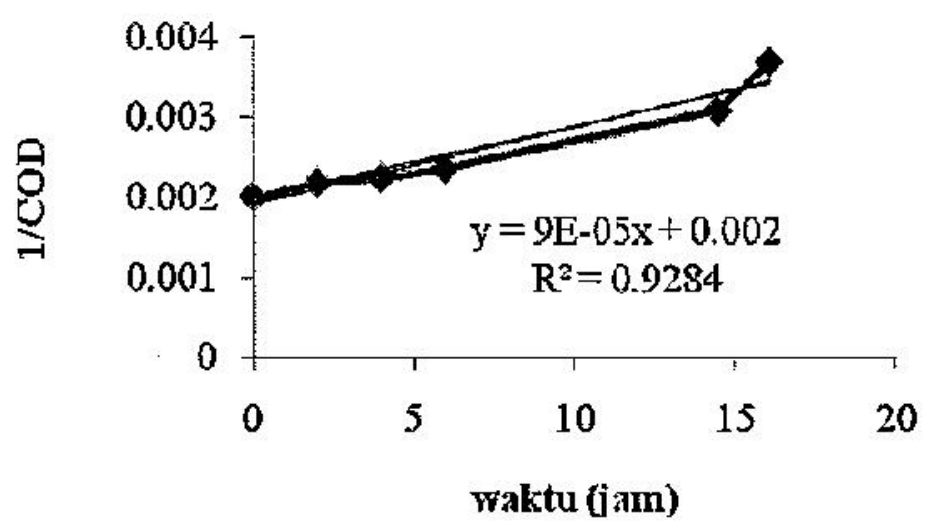

Gambar 5. Pengujian Reaksi Orde 2 
Jika diperhatikan grafik di atas dilihat dari nilai $\mathrm{R}^{2}$ dapat disimpulkan balıwa orde reaksi penurunan $C O D$ pada limbah ini adalah orde 1 , dengan konstanta kecepatan reaksi sebesar 0,034 jam $^{-1}$. Jadi persamaan umum untuk penurunan COD dalam limbah yang mengandung detergen Persil dirumuskan dengan Persamaan (16).

$$
-\mathrm{r}_{\mathrm{COD}}=\frac{\mathrm{d}[\mathrm{COD}]}{\mathrm{dt}}=0,034[\mathrm{COD}]^{1}
$$

Berdasarkan nilai $\mathrm{k} 0,034$ jam $^{-1}$ dapat dikatakan bahwa nilai ini relatif kecil atau penurunan COD kurang cepat. Hal ini disebabkan oleh detergen Persil mengandung Zeolit sekitar $15-30 \%$ yang tidak akan terdcgradasi olch Ozon. Berdasarkan alasan pemilihan detergen Persil adalah untuk mengurangi dampak buih pada proses evaporasi, penelitian dilanjutkan dengan mengganti detergen menjadi detergen biasa yang hargaya jauh lebih murah (Rinso Anti Noda).

Berikut di bawah ini adalah data ozononasj dengan menggunakan Rinso anti noda sebagai data perbandingan.

Tabel 5. Data Ozonasi Rinso dengan Waktu 1 Jam Konsentrasi Awal 1,496 g/L

\begin{tabular}{|c|c|c|c|c|}
\hline \multicolumn{3}{|c|}{ Sebelum ozonasi } & \multicolumn{2}{|c|}{ Sesudah ozonasi } \\
\hline $\mathrm{COD}$ & $: 440$ & $\mathrm{ppm}$ & COD & : $94,992 \mathrm{ppm}$ \\
\hline TS & $: 1308$ & ppm & $\mathrm{TS}$ & $: 796$ \\
\hline $\mathrm{pH}$ & 9 & & $\mathrm{pH}$ & $: 6$ \\
\hline
\end{tabular}

Konsentrasi Rinso dibuat sama dengan dengan deterjen Persil yang digunakan sebagai limbah simulasi dan sama-sama mengandung $51 \mathrm{ppm}$ Cesium. Dengan waktu ozonasi 1 jam penurunan COD dan TS sangat signifikan. Jika degradasi limbah simulasi dengan Rinso ini diasumsikan reaksi orde satu, maka konstanta kecepatan reaksi $\mathrm{k}$ untuk Rinso $1,5443 \mathrm{jam}^{-1}$, untuk deterjen Persil 0,034 $\mathrm{jam}^{-1}$ atau $\mathrm{k}$ untuk degradasi limbah simulasi dengan detergen Rinso $45 \mathrm{kali}$ lebih besar dari pada $\mathrm{k}$ untuk limbah simulasi dengan detergen Persil. Berdasarkan hasil tersebut dimungkinkan bahwa komposisi deterjen Persil sangat sulit terdegradasi dengan ozonasi. Dilihat dari komposisi deterjen Persil komposisi terbesar adalah zeolit sebesar $15-30 \%$, dan surfaktan anion 5-15\%. Fungsi zeolit dalam deterjen untuk meningkatkan daya pencucian untuk menjerap kotaran. Kandungan zcolit yang dalam deterjen menjadi salah satu penyebab turunnya TS pada limabah deterjen Persil tidak signifikan. Ditinjau dari surfaktan, mungkin surfaktan anion yang dipakai adakah jenis alkil benzene sulfonat dengan rantai yang bercabang-cabang. Menurut pustaka alkil benzene sulfonat dengan rantai cabang merupakan komponen "non degradable", oleh karena itu deterjen sekarang pada umumnya menggunakan surfaktan linear alkilbenzen sulfonat dengan senyawa rantai lurus sehingga mudah terdegradasi. Jika dilihat dari hasil degradasi Rinso diduga bahwa deterjen Rinso menggunakan surfaktan anion jenis linear alkilbenzen sulfonat yang mudah terdegradasi serta diduga tidak terdapat zeolit dalam deterjen Rinso. Pada kemasan Rinso juga ditulis "ramah lingkungan" walaupun pada kemasan Rinso tidak dicantumkan komposisinya.

\section{Penjerapan Cs setelah Ozonasi}

Tabel 6 adalah hasil proses penjerapan dengan zeolit setelah melewati proses ozonasi. Efisiensi proses penjerapan paling tinggi $99,314 \%$ dengan nilai FD 145,773 . 
Tabel 6. Data Konsentrasi Cesium setelah Penjerapan, (Cs mula-mula=51,0204 ppm)

\begin{tabular}{cccc}
\hline $\begin{array}{c}\text { Cs sesudah } \\
\text { penjerapan } \\
\text { (ppm) }\end{array}$ & FD & EP \% & $\begin{array}{c}\text { Cs terjerap zco- } \\
\text { lit (meq/g Zeo- } \\
\text { lit) }\end{array}$ \\
\hline 0,388 & 131,496 & 99,2395 & 0,03807 \\
0,400 & 127,551 & 99,2160 & 0,03806 \\
0,350 & 145,773 & 99,3140 & 0,03810 \\
0,358 & 142,515 & 99,2983 & 0,03809 \\
0,394 & 129,493 & 99,2278 & 0,03806 \\
0,396 & 128,839 & 99,2238 & 0,03806 \\
\hline
\end{tabular}

\section{KESIMPULAN}

Berdasarkan penelitian yang telah dilakukan dapat diambil kesimpulan sebagai berikut.

1. Metode ozonasi diikuti penjerapan dengan zeolit dapat digunakan untuk mengolah limbah radioaktif cair yang mengandung deterjen.

2. Persamaan kecepatan penurunan COD dalam limbah radioaktif cair yang mengandung deterjen Perseil adalah sebagai berikut:

$-\mathrm{r}_{\mathrm{COD}}=-\frac{\mathrm{d}[\mathrm{COD}]}{d t}=0,034[\mathrm{COD}]^{1}$

yang berarti reaksi orde 1 dengan nilai $\mathrm{k} 0,034 \mathrm{jam}^{-1}$.

3. Nilai kontante kecepatan reaksi dengan detergen biasa memberikan nilai $\mathrm{k}$ $1,5443 \mathrm{jam}^{-1}$.

4. Nilai FD dan EP dari proses penjerapan sebesar 145,773 dan $99,314 \%$.

\section{UCAPAN TERIMA KASIH}

Penyusun mengucapkan terima kasih kepada Sdr.Maria Christina Prihatiningsih dan Sdr. Kartini Megasasri atas masukan dan bantuan dalam menganalisis hail proses.

\section{DAFTAR PUSTAKA}

Alacrt, G dan Santika, S. S. 1987. Metoda Penelitian Air. Surabaya: Usaha Nasional,

Bismo, S, Kustiningsih, I, Jayanudin, Haryanto, F, dan Saptono, H. J. 2008. Studi Awal Degradasi Fenol Dengan Teknik Ozonasi Di Dalam Reaktor Amular. Semarang: Prosiding Seminar Nasional Rekayasa Kimia Dan Proses ISSN: 1411-4216, Jurusan Teknik Kimia FT-UNDIP.

Dharmayanti, E. 2002. Efektifitas Pengolahan Limbah Cair Thorium - 232 Simulasi Dengan Zeolit Dan Bentonit Secara Catu. Yogyakarta: Tugas Akhir STTN-BATAN.

Dogra S. K dan Dogra S. 1990. Kimia Fisik Dan Soal-Soal. Jakarta: Universitas Indonesia 
Enjarlis, Bismo, S, Slamet, dan Roekmijati. 2006. Studi Pendahuluan Ozonasi (katalitik dan Non Katalitik) Limbah Cair Karbofuran. Scmarang: Reaktor Vol.10 No.2 Desember 2006 ISSN: 0852-0798 Jurusan Teknik Kimia FTUNDIP.

Gunandjar, Salimin, Z, Purnomo, S, dan Ratiko. 2009. Proses Oksidasi Biokimia Untuk Pengolahan Limbah Simulasi Cair Organik Radioaktif. Yogyakarta: Seminar Nasional V SDM Tcknologi Nuklir ISSN 1978-0176.

http:/file.upi.edu/Direktori/D\%20\%20FPMIPA/JUR.\%20PEND.\%20KIMIN/196 $80161994022 \% 20 \% 20$ SOJA\%20SITI\%20FATIMAH/Kimia\%20industri/I NDUSTRL\%20DETERJEN.pdf diakses pada tanggal 6 Juni 2011 pukul 19.50 WIB.

http://www.lenntech.com/ozone/ozone-properties.htm diakses pada tanggal 6 Maret 2010 pukul 16.31 WIB.

htlp:/www.lenntech.com/library/ozone/decomposition/ozone-decomposition.htm diakses pada tanggal 6 Maret 2010 pukul 17.05 WIB.

http://smk3ae.wordpresss.com/2008/07/15/metode-pengolahan-deterien diakses pada tanggal 14 Juni 20011 pukul 16.52 WTB.

Isyuniarto dan Purwadi, A. 2006. Kajian Penggunaan Ozon Pada Pengolahan Limbah Caì Industri Udang. Yogyakarta: Jurnal Iptck Nuklir GANENDRA ISSN 1410-6957 Volume IX No.1 Januari 1006 PTAPB BATAN.

Kundari, N. A. 2008. Tinjauan Kesetimbangan Adsorpsi Tembaga Dalam Limbah Pencuci PCB Dengan Zeolit. Yogyakarta: Seminar Nasional IV SDM Teknologi Nuklir ISSN 1978-0176.

Levenspiel, O. 1999. Chemical Reaction Engineering Third Edition. New York: Department of Chemical Engineering Oregon State University, John Wiley \& Sons.

Mardini, Muziyawati, A, dan Aji, D. 2006. Analisis Limbah Radioaktif Cair dan Semi Cair. Serpong: Hasil Penelitian dan Kegiatan PTLR Tahun 2006 PTLR-BATAN.

McCabe, W. L, Smith, J. C, dan Harriou, P. 1989. Unit Operation Of Chemical Enginering. Fourt Edition. New York: McGraw-Hill Book Inc.

Namboodri, C.G dan Perkins, W.S. 1994. Decoloring Dyes With Chlorine And Ozone: Part II.

Auburn:Enginering Department Auburn University, Alabama.

Pambudi, S. L. 2009. Adsorpsi Fenol Dalam Limbah Dengan Zeolit Alam Terkalsinasi. Yogyakarta: Tugas Akhir STTN-BATAN. 
Pitaadmadja, Y D. 2001. Penentuan Daya Adsorpsi Zeolit Bandung dan Zeolit Malang Terhadap Rhodamin-B, Biru Metilen, Kinin HCl dengan Attapulgit. Surabaya: Skripsi Fakultas FarmasimUniversitas

Purba, M. 2004. Kimia Untuk SMA Kelas XI 2B. Jakarta: Erlangga.

Salimin, Z. 2002. Pengolahan Limbah Radioakrif Cair Aktifitas Rendah Yang Mengandung Deterjen Persil Dengan Proses Oksidasi Biokimia. Bogor: Tesis Program Pasca Sarjana-[PB.

Setyawan, D. E. 2010. Kinetika Degradasi RemazolBrillian Blue Menggunakan Ozon Dalam Reaktor Alir Pipa. Yogyakarta: Tugas Akhir STTN-BATAN.

Suardana, I. N. 2008. Optimalisasi Daya Adsorpsi Zeolit Terhadap ion Kromium (III). Bali: JPPSH Jurusan Pendidikan Kimia FMIPA- Undiksha.

Suhartanto, A. 1999. Pemisahan Compuran Uranium dan Molibdenum Menggunakan Zeolit. Yogyakarta: Tugas Akhir PATN-BATAN.

Supriyono dan Pujiastuty, H. Penggunaan Zeolit Aktif Dan Arang Aktif Pada Penurunan Kadar Mangan (Mn). Surakarta: Jurnal Kimia dan Teknologi ISSN 0216-163X Jurusan Analis Kimia FT-Universitas Setia Budi.

Suyanti. 2002. Pengambilan Uranium, Cesium Dan Rutenium Dari Limbah Simulasi Dengan Zeolit Gunung Kidul. Yogyakarta: Tugas Akhir STTN-BATAN.

UU No.10 tahun 1997 Peraturan Pemerintah Nomor 27 tahun 2002 Pasal 1 dan 4.

Wardhana, W. A. 2004. Dampuk Pencemaran Linghungan Edisi Revisi. Yogyakarta: Andi-Offsct.

E-mailjjfnsttn@gmail.com 